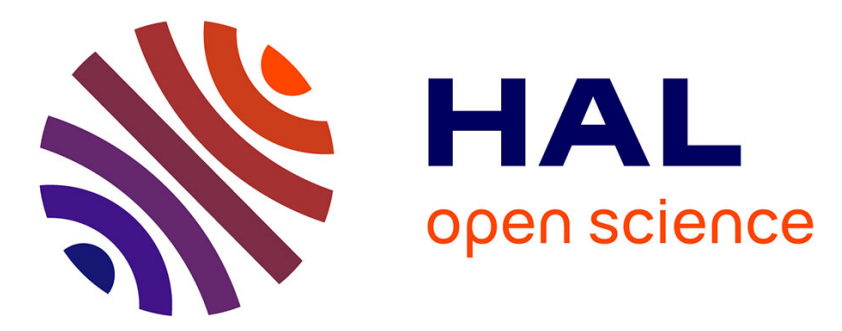

\title{
Populating soil maps with legacy data from a soil testing databases
}

Jean-Baptiste Paroissien, Nicolas Saby, Benjamin Louis, Dominique Arrouays

\section{To cite this version:}

Jean-Baptiste Paroissien, Nicolas Saby, Benjamin Louis, Dominique Arrouays. Populating soil maps with legacy data from a soil testing databases. GlobalSoilMap, Oct 2013, Orléans, France. 2014. hal-01190639

\section{HAL Id: hal-01190639 \\ https://hal.science/hal-01190639}

Submitted on 1 Sep 2015

HAL is a multi-disciplinary open access archive for the deposit and dissemination of scientific research documents, whether they are published or not. The documents may come from teaching and research institutions in France or abroad, or from public or private research centers.
L'archive ouverte pluridisciplinaire HAL, est destinée au dépôt et à la diffusion de documents scientifiques de niveau recherche, publiés ou non, émanant des établissements d'enseignement et de recherche français ou étrangers, des laboratoires publics ou privés. 


\title{
Populating soil maps with legacy data from
} a soil testing databases

J-B. Paroissien ${ }^{1}$, N.P.A. Saby ${ }^{1}$, B. Louis ${ }^{2}$, A.C. Richer de Forges $^{1} \&$ D. Arrouays ${ }^{1}$ INRA, US1106 InfoSol, F-45075 Orléans, France

INRA, UMR1069, Sol Agro et hydrosystème Spatialisation, F-35000 Rennes, France

\begin{abstract}
In France, soil test results from samples of cultivated topsoil requested by farmers have been collected to constitute the National Soil Testing database (NSTD). Enriching soil maps with such data can be regarded as an important source of information to build GlobalSoilMap products when dense soil profile information does not exist

$\longrightarrow$ We inferred the soil organic carbon content (SOC) distribution within the soil units of a soil map in a central region of France to re-allocated analyses from NSTD

$\longrightarrow$ The method is based on a pedological distance between the soil properties (pH, CaCO3 content, cation-exchange capacity, clay content and silt content) of the NSTD and soil $\longrightarrow$ map units mean values of the same parameters

$\longrightarrow$ Results showed a consistent spatial distribution of SOC content
\end{abstract}

\section{Context}

NSTD offers the advantage to gather a very large number of analytical results since 1990 but these analytical results were not originally intended for the purposes of soil mapping (Schvartz et al., 1997). The legacy soil data do not always include information about the statistical distribution within spatial unit of the soil properties (min, max and modal). Allocations of NSTD to soil map units may allow supplying a better statistical description of these distributions of their properties.

\section{Methods}

1. "Loiret", the study area

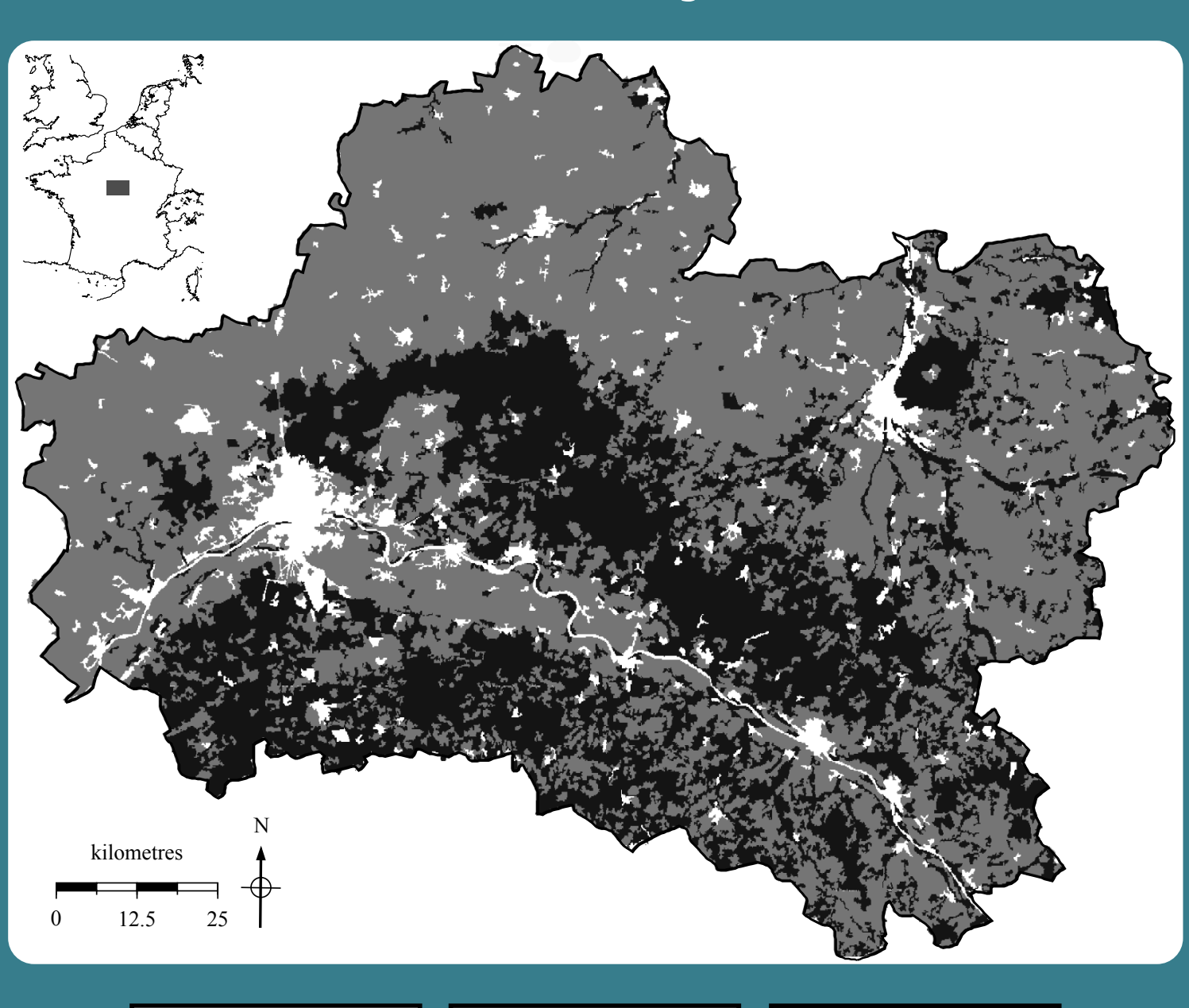

Databases used

NSTD : 12594 topsoil samples spreaded into 327 municipalities

Map of Loiret : 291 Soil Typological Units (STU) \& 95 Soil Maps Units (SMU)
2. Overlay between communes and the soil map

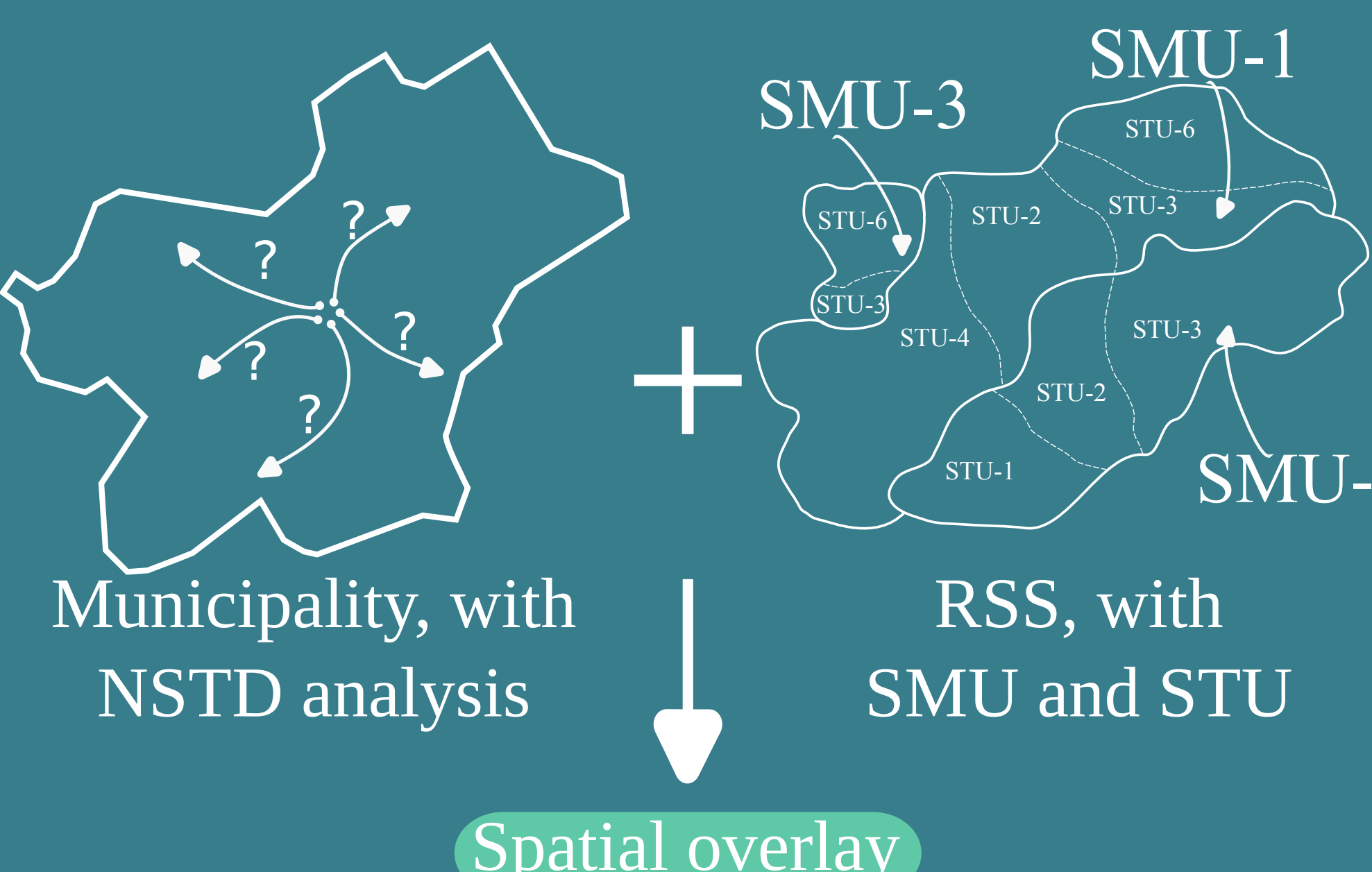

Spatial overlay
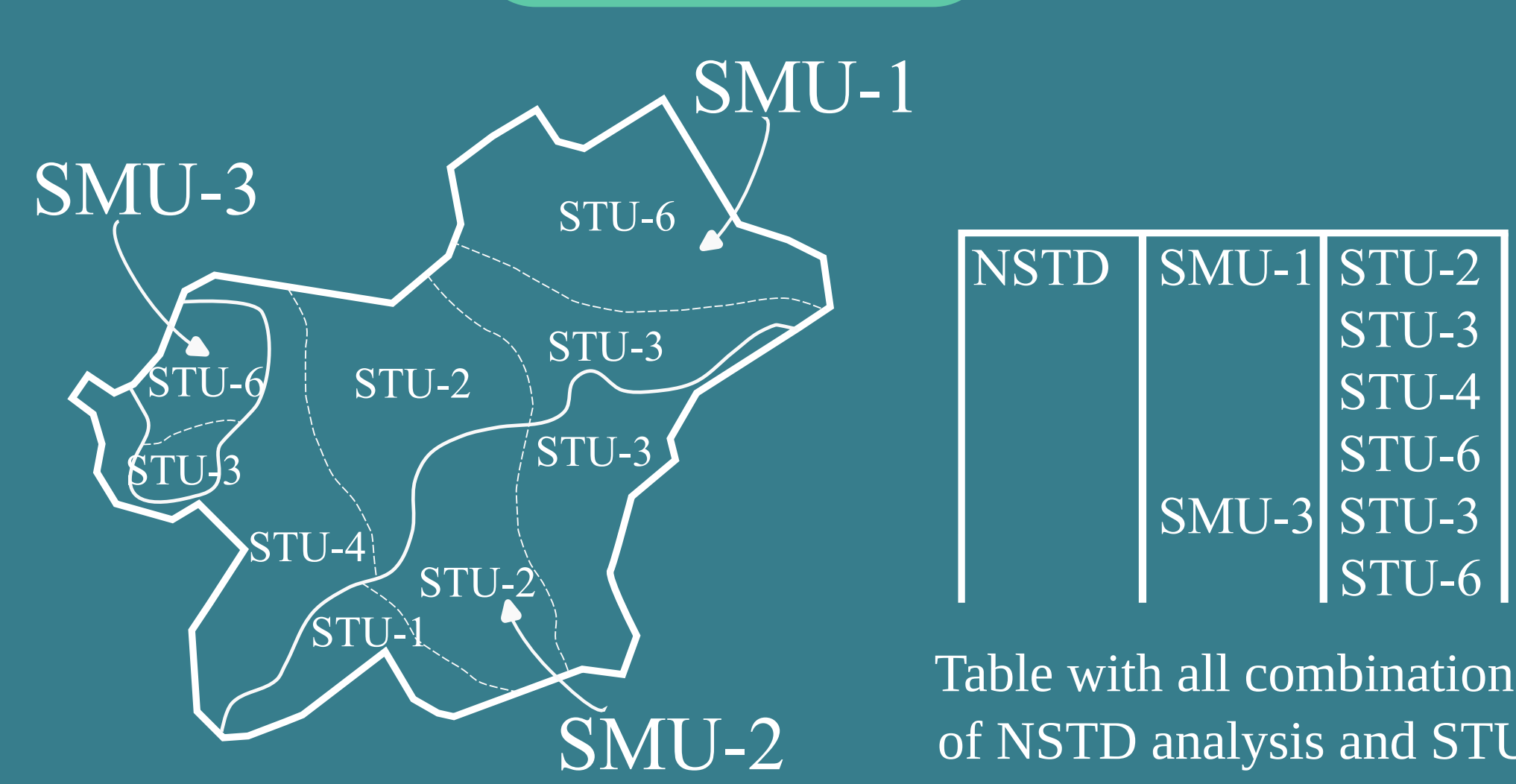

af NSTD all combinations

\section{Results}

1. Maps of SOC content (no data areas are in color white)
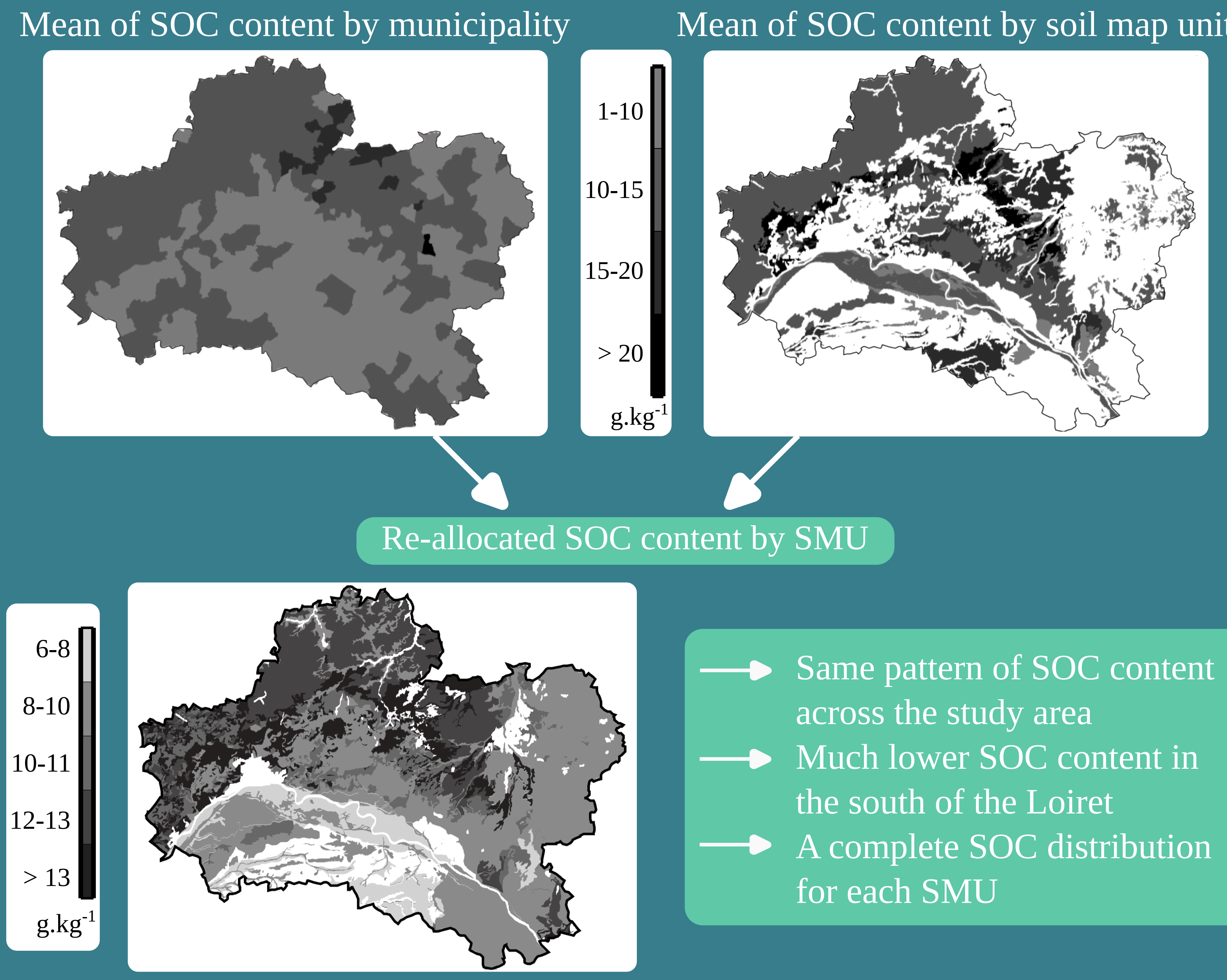

$\longrightarrow$ Same pattern of SOC content across the study area

$\longrightarrow$ Much lower SOC content in the south of the Loiret

$\longrightarrow$ A complete SOC distribution for each SMU

\section{Aim}

$\longrightarrow$ Re-allocate soil organic carbon content analysis from soil testing database to soil map units of the Regional Soil Survey (RSS) (Richer de Forges 2008) of the French department "Loiret"

$\longrightarrow$ Compute a pedological distance (Carré et al., 2009) between soil properties (pH, $\mathrm{CaCO} 3$ content, clay content, silt content and sand content) of the NSTD analyses and soil map units mean values

3. Calculating pedological distance 4. Aggregating values by SMU The Euclidean distance is calculated using The pedological distance is then used as a Principal Component Analysis (PCA) selection criteria. Analyzes with built from the modal values of soil pedological distance lower than the 10th properties of the STU as active variables. quantile calculated using the distribution of

$\begin{array}{cc}\text { Pedological criteria used are : } & \text { all the } \\ \text { soil texture, } \mathrm{pH} \text { and } \mathrm{CaCO}_{3} & \text { STU }\end{array}$

The values of the soil properties from NSTD analysis are introduced in the PCA as supplementary variables. A matrix containing the PCA coordinates of all combinations of NSTD analysis and STU is built and used to calculate a pedological distance following this formula :

$$
d_{i, j}=\sqrt{\sum_{k} w_{k}\left(x_{i, k}-x_{j, k}\right)^{2}}
$$

$x_{i, k}$ is the PCA coordinate of NSTD analysis for the principal component $k . x_{j, k}$ is the PCA coordinates of STU $j$ for the principal component $k . w_{k}$ is the percentage of variance explained by principal component the distances are assigned to the selected STU.

To map SOC, we first computed the
mean of NSTD SOC analyses
for each STU and then calculated
the weighted mean of each SMU

\section{Validation procedure}

A part of NSTD ( $80 \%$ randomly selected) in each commune is used to populate the regional soil survey. The NSTD SOC analyses kept apart were aggregated by commune to calculate the mean of SOC by SMU. This dataset is named SOC datase validation.

Open-source software used

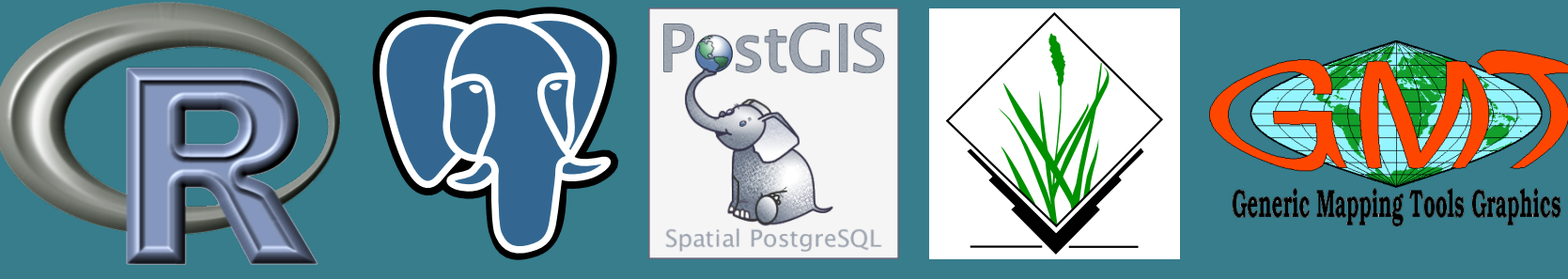

\section{Validation results}
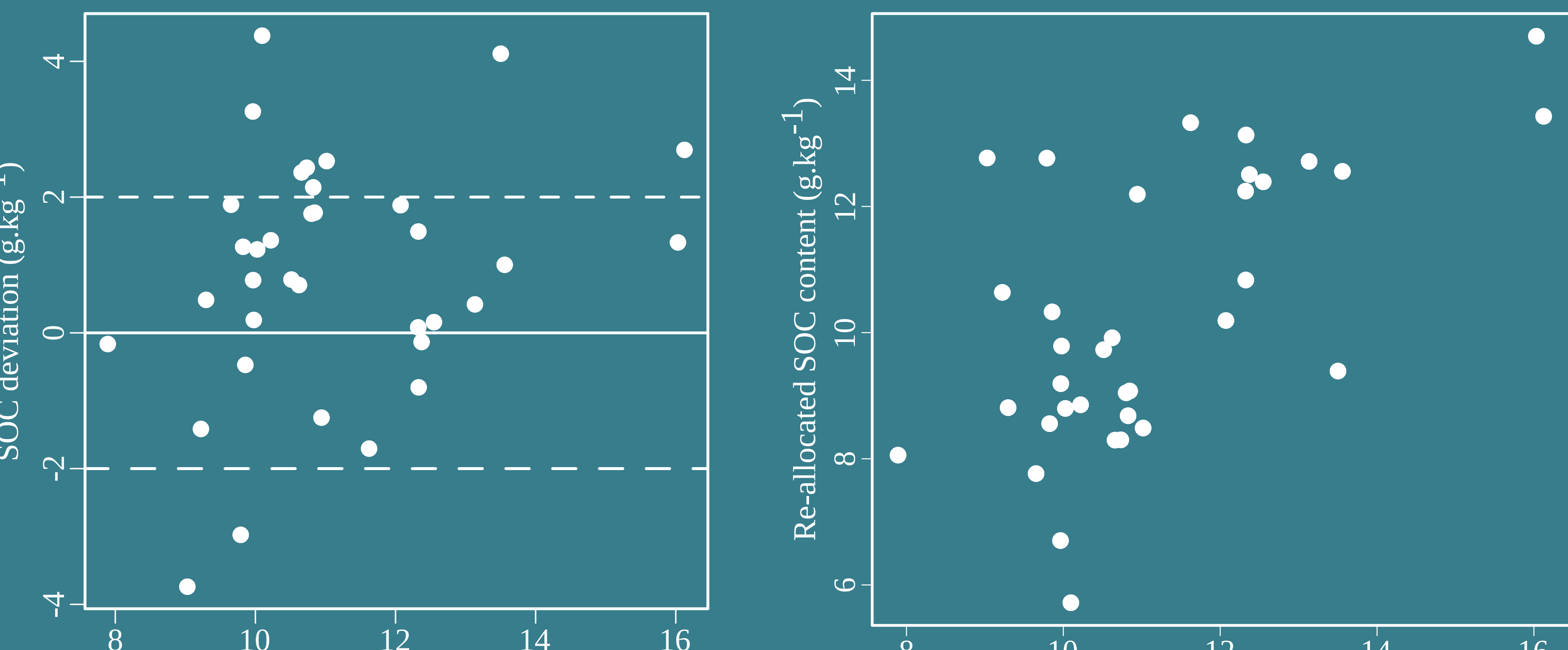

SOC dataset validation (g.kg $\left.{ }^{-1}\right)$

The deviation of the method is uniform along the range of NSTD values

$\longrightarrow 71 \%$ of analyses are inside the envelope of acceptance
Significant correlation between dataset validation and re-allocated SOC content

$\rightarrow \mathrm{R}^{2}: 0.4$

$\longrightarrow$ RMSE $: 2 \mathrm{~g} \cdot \mathrm{kg}^{-1}$

\section{Conclusion}

The principle of pedological distance has already shown good results in the prediction of soil classes (Carré et al., 2009). In this study, the results are consistent with the reference map. In the framework of GlobalSoilMap the main interest of this method is to populate existing soil maps to provide a better estimate of the range of values of a given soil

\section{References}

